\title{
A Relationship Examination of Uncertainty Avoidance, Guanxi Building and Organisational Socialisation among Newcomers
}

\author{
Yiye Zhang \\ School of Performance and Cultural Industries \\ University of Leeds \\ Leeds, West Yorkshire, UK \\ ml12y25z@leeds.ac.uk
}

\begin{abstract}
In the current career climate characterised by rapid change and turbulence, employees with high uncertainty avoidance may develop psychological attachment to their peers and supervisors in order to increase organisational socialisation. The present study aims to investigate the impact of uncertainty avoidance and guanxi building with peers and supervisors among new joiners on organisational socialisation.
\end{abstract}

Keywords-uncertainty avoidance; organisational socialisation; guanxi building

\section{INTRODUCTION}

A number of companies in China are facing a phenomenon that newcomers, especially during the first two years after joining an organisation, are keen on building guanxi with their peers and supervisors. Though this kind of behaviour is sometimes seen as a breeding ground for corruption, newcomers with a good interpersonal network tend to get more closely involved in their team and cooperation between the newcomers and other team members is smoother. Previous research have shown that guanxi ties and networks can be seen as social resources [1][2] which people develop for favours and benefits such as resources, better job placement and organisational performance for firms [1]. This article focuses on discussing the reasons for, and effects of, building such guanxi.

Guanxi, represents a type of Chinese social system, is a mainland conception which deals with high individual problem and vague social changeable mechanism [3].Previous research about the motivation of building guanxi mainly focuses on special needs such as loyalty and commitment, and resources, information and communication, rather than the rationale of uncertainty avoidance. However, analogous research to this article point to variables such as turnover intentions and hiring patterns between individuals and organisations to explain the behaviour of such employees [4]. Since people with high uncertainty avoidance tend to have more pressures and anxieties than others when they join a new organisation, they have less job insecurities but higher turnover intentions. Thus, in order to lower the uncertainty of newcomers, organisations can establish rules and standards and also develop a system of organisational support. In addition, individuals receive resources and information from guanxi ties with their peers and supervisors to gain a sense of belonging and lower their uncertainty. Therefore, this research considers uncertainty avoidance as a reason why newcomers prefer building guanxi with their peers and supervisors.

In addition to several other effects that building guanxi has, such as performance and trust [2][5], organisational socialisation is a consequence which is important in order for newcomers to adapt to their organizations as soon as possible. There is a stream of research arguing that a major way to make socialization happen is to go through social interactions between insiders and outsiders [6][7]. That is to say, if new joiners want to be members of their respective organisations both mentally and physically, one way to achieve this is to build a good interpersonal network with their co-workers and leaders. Though research and theory suggest that building guanxi may be very important in order for new workers to learn and communicate effectively, the existing organizational socialization literature has not focused on interpersonal networks [8][9]. Guanxi might be important, but little is known about the types of guanxi patterns that are most conducive to organizational socialization.

The aim of this study is to elicit whether the high level of uncertainty avoidance could cause the motivation to create and keep guanxi with peers and supervisors. Therefore, organizational socialization can be carried through reaching certain resources to strengthen the sense of belonging and the degree of participation.

\section{HYPOTHESIS}

\section{A. Uncertainty Avoidance and Guanxi Building}

Uncertainty avoidance, defined as the extent of threat occurred in certain society when uncertainty and ambiguity happened [10], is usually considered as a variable examination cross culture effects, and it also has different influences on employees from the same organization. When newcomers join an organization, they have to undergo a period from being unfamiliar to being familiar with it, under competitive pressure from peers. If some of them have high level uncertainty avoidance, they will tend to experience more anxieties and insecurities, which may have negative effects. However, even if organizational support and useful official information can lower the uncertainty, newcomers with high uncertainty 
avoidance do not always trust such support and information. They may find other ways to gain resources to reduce pressure.

From a theoretical standpoint, even though uncertainty avoidance has been used to measure multicultural situations, people from same culture also have different backgrounds and characteristics. Facing uncertainty, different people have different options to deal with resultant high pressure. Uncertainty reduction theory posits that newcomers expect to lower the unpredictability by interacting with others in the new organization [11].

It is suggested that channels of disseminating official information in some Chinese organizations is not perfect and therefore employees, especially newcomers with high uncertainty avoidance, consider that information and resources gained from official channels are not responsive to their needs. There is, however, often a multitude of grey information that can be dug out by use of guanxi networks. This is particularly prominent in Chinese organisations, as interpersonal networks which have been maintained for thousands of years tend to benefit people more than regular methods. Moreover, guanxi practice can be referred to the use of interpersonal relations for reaching other objectives in work and life [12]. Newcomers with high uncertainty avoidance believe that through building guanxi with peers and supervisors, more information and resources can be gained in order to fulfil their needs and lower uncertainties.

In order to receive information and develop a sense of belonging, high uncertainty avoidance employees tend to build guanxi with their peers. Due to the fact that some methods and knowledge for dealing with daily routine are usually from experiences accumulated from years of working rather than primitive theory that kind of information cannot be found in official documents, such as labour manuals. Even though such information can be built up through years of experience, newcomers with high uncertainty avoidance may find it difficult. If they can not get the knowledge from official information, they will chase it by building guanxi with supervisors. Besides, organizational options have certain rules and procedures which usually cannot be found in official documents. Thus, building guanxi with peers becomes an important way for newcomers who are unfamiliar with conditions to get a sense of belonging and security in order to lower their uncertainty.

Newcomers with high uncertainty avoidance are eager to build guanxi with supervisors to gain certain resources and career success. To some extent, personnel selection, performance appraisal, and rewards allocation are connected with good guanxi with supervisors [5]. Although high uncertainty avoidance newcomers may be affected by high pressures and turnover intentions, they can be settled down and increase certainty by being given appropriate positions and/or frequent appraisals. In the supervisor-subordinate guanxi research, guanxi activities outside the working environment provide strong guanxi quality which benefits both of them. Therefore, building and maintaining guanxi with supervisors usually has positive effects for the newcomers with high uncertainty avoidance.
Hypothesis1. Uncertainty avoidance will affect the newcomers' behaviour of guanxi building.

H1a. Uncertainty avoidance and guanxi building with peers have positive correlation.

H1b. Uncertainty avoidance and guanxi building with supervisors have positive correlation.

\section{B. Guanxi Building and Organizational Socialization}

Organizational socialization is considered as a process which newcomers make the transition to adjust new values, attitudes, behaviors and become insiders. [13] Given the fact that organizational socialization has many positive impacts on a newcomer's career, such as higher performance, positive attitude, organizational commitment, and organizational adaption, organizations are willing to promote socialization in newcomers. [6] One of the most important tasks which must be accomplished for organisational socialisation is learning, which requires newcomers to acquire a wide range of new information proactively. [14] In particular, insiders may forget the importance of information communication with newcomers, and newcomers may only be given information about important task mastery only if or when they are accepted by insiders [12] and these are the reasons why proactive learning is important in order for newcomers to become insiders. This learning process involves almost all kinds of information which make newcomers become insiders, including task mastery, role clarification, acculturation, and social integration [15]. In order to complete the learning process, newcomers choose tactics, like overt questions and third party, testing, disguising conversations, observing, and surveillance to gain information. [16] In summary, all the tactics needed to build and maintain good guanxi network with peers and supervisors. It is important for a newcomer to find the right person to give knowledge about the organization, work team, and career.

Previous research has shown that guanxi ties do not only have positive effects on performance [2], but also benefits relating to trust, knowledge sharing and employee satisfaction. During the guanxi building period, values and goals of newcomers change through learning and communicating with peers and supervisors. That is mainly because of the desire of new joiners to become insiders by imitating the talking and working behaviours of their peers and supervisors proactively. Through this process, organizational culture has been spread. Meanwhile, newcomers get co-workers' and supervisors' support through guanxi building, so useful information and resources can be gained more easily than by those who fail to build guanxi network. Therefore, guanxi building is an important path towards organizational socialization.

Peers may have relationships ranging from very distant to very close. If the guanxi building with peers is successful, newcomers will get both expressive and instrumental exchanges [17]. Expressive exchanges between peers can happen in non-job-related incidents like giving gifts, having dinners, or sharing personal problems. Newcomers can gain acceptance and trust through expressive exchanges. Meanwhile, instrumental exchanges are more related to work, including communicating about work problems or conflicts, cooperating in tasks, and sharing experiences about work. Role clarification 
and task mastery can be achieved by instrumental exchanges. Thus, an interaction between outsiders and insiders has completed and newcomers have the intention to accomplish organizational socialization.

Socialization theory also suggests that access to useful information and resources might be gained from dive new members in an organization, such as employees from different departments in an organization. Although peers are important in newcomers organizational socialization, people at higher level in the organization may be better sources for certain types of resources than those at lower levels [7]. To some extent, task and social integration can be learned more easily from supervisors than just from peers, because the former have greater understanding towards newcomers' responsibilities and greater information and resources. Therefore, newcomers are willing to build guanxi with supervisors in order to get more resources and support in order to fulfill their needs and achieve their goals. Since communication happens between newcomers and leaders in order to ensure the former have a deeper understanding towards the organization, organizational socialization can also be carried out.

Hypothesis 2. Newcomers' organizational socialization will be positively related to guanxi building.

H2a. Guanxi building with peers and organizational socialization have positive correlation.

H2b. Guanxi building with supervisors and organizational socialization have positive correlation.

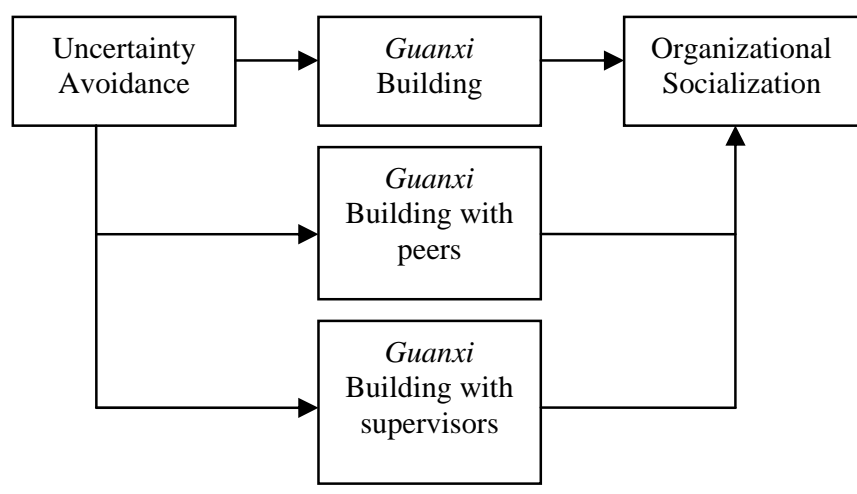

GRAPH I. MODEL OF THIS RESEARCH

\section{CONCLUSION}

Overall, the model of this research describes a possible causality among uncertainty avoidance, guanxi building and organizational socialization. For the motivation of guanxi building, this research illustrates that uncertainty avoidance has the positive effect of promoting guanxi ties with peers and supervisors. This is consistent with the important role that information seeking plays in uncertainty reduction. For the outcome of guanxi building, organizational socialization is used to test the benefits people can get from guanxi ties with peers and supervisors.

This study has both theoretical and practical implications. Although several issues warrant further investigation, this study provides a useful first look at the relationship between uncertainty avoidance and guanxi building. It also suggests that further investigation will be fruitful. Most importantly, it suggests that organizations should recognize the uncertainty of newcomers, and after recognising this should seek to fulfil their needs. A newcomer needs an informational guanxi network for acquiring various types of information and resources, and he or she needs an interpersonal guanxi network for a sense of belonging to the organization. Organizations should encourage newcomers to build optimal guanxi networks with peers and supervisors. Individuals from the organizations are responsible for helping newcomers lower their uncertainty and bringing them "on board". Newcomers should let communication happen voluntarily in order to become "insiders" as quickly as possible.

\section{REFERENCES}

[1] Bian, Y. Bringing Strong Ties Back in: Indirect Ties, Network Bridges, and Job Searches in China. American Sociological Review. 1997, 62(3): 366-385.

[2] Luo, Y. Guanxi: Principles, Philosophies, and Implications. Human Systems Management. 1997a, 16(1): 43.

[3] Alston J Wa. Guanxi and Inwa: Managerial Principles in Japan, China, and Korea. Business Horizon. 1989, March-April: 26-31.

[4] Withey, M. J., Cooper, W. H. Predicting Exist, Voice, Loyalty and Neglect. Administrative Science Quarterly. 1989:521-539.

[5] Chen, C. C., Ya-Ru Chen, \& Xin, K. Guanxi Practices and Trust in Management: A Procedural Justice Perspective. Organization Science. 2004, 15(2): 200-209.

[6] Feldman, D. C. The Multiple Socialization of Organization Members. Academy of Management Review. 1981, 6: 309-318.

[7] Louis, M. R. Acculturation in the Workplace: Newcomers as Lay Ethnographers. In B. Schneider (Ed.), Organizational Climate and Culture. San Francisco: Jossey-Bass. 1990: 85-129.

[8] Brass, D. J. A Social Network Perspective on Human Resources Management. In G. R. Ferris (Ed.). Research in Personnel and Human Resources Management. 1995, 13: 39-79.

[9] Ibarra, H. Race, Opportunity, and Diversity of Social Circles in Managerial Networks. Acadeiny of Management Journal. 1995, 38: 673703.

[10] Hofstede, G. Culture's Consequences: International Differences in Work-related Values. Newbury Park, CA: Sage. 1980.

[11] Berger, C. R., \& Calabrese, R. J. Some Explorations in Initial Interaction and Beyond: Toward a Developmental Theory of Interpersonal Communication. Human Communication Research. 1975, 1: 99-112.

[12] Guthrie, D. The Declining Significance of Guanxi in China's Economic Transition. China Quarterly. 1998, 154: 254-282.

[13] Louis M R. Surprise and Sense Making What Newcomers Experience in Entering Unfamiliar Organizational Settings. Administrative Science Quarterly. 1980, 25: 226-251.

[14] Ashforth B. E., Saks A. M. Socialization Tactics: Longitudinal Effects on Newcomer Adjustment. Academy of Management Journal. 1996, 39(1):149-178.

[15] Feldman, Daniel Charles. The Multiple Socialization of Organization Members. Academy of Management Review. 1976, APr81,6(2):309-318.

[16] Fisher C. D. Organizational Socialization: an Integrative Review. In Rowland K. M, Ferris G. R. (Eds) Research in Personnal and Human Resources Management. Greenwich, CT: JAI Press. 1986, 4: 101-145.

[17] Chen, X.-P. \& Peng, S. Guanxi Dynamics: Shifts in the Closeness of Ties between Chinese Coworkers. Management and Organization Review. 2008, 4(1): 63-80.

[18] Dorfman, P. W. Howell, J. P. Dimensions of National Culture and Effective Leadership Patterns: Hofstede Revisited. Advances in International Comparative Management. 1988, (3): 127-150. 
[19] Law, K. S., Wong, C., Wang, D., \& Wang, L. Effect of Supervisor-subordinate Guanxi on Supervisory Decisions in China: An Empirical Investigation. International Journal of Human Resource Management. 2000, 11(4): 751-765.

[20] Haueter, J. A., Macan, T. F. \& Winter, J. Measurement of Newcomer Socialization: Construct Validation of a Multidimensional scale [J]. Journal of Vocational Behavior. 2003,63: 20-39.

\section{APPENDIX}

Items measuring uncertainty avoidance ${ }^{[18]}(1=$ Strongly disagree, $2=$ Disagree, $3=$ Neutral, $4=$ Agree, $5=$ Strongly agree)

1. It is important to have job instructions spelled out in detail so that I always know what they are expected to do.

2. Rules and regulations are important because they inform me what the organization expects of them.

3. Standard operating procedures are helpful to me on the job.

4. Instructions for operations are important for me on the job.

Items measuring guanxi building with peers ${ }^{[19]}(1=$ strongly disagree, 7 = strongly agree).

1. During holidays or after office hours, 1 would call my peers, who are closer with me, or visit them.

2. I invite my peers, who are closer with me, for lunch or dinner.

3. On special occasions such as birthday of my peers, who are closer with me, I would definitely visit them and send gifts.

4. I always actively share with my peers, who are closer with me, about my thoughts, problems, needs and feelings.

5. I care about and have a good understanding of the families and work conditions of my peers, who are closer with me. 6 . When there are conflicting opinions, I will stand on my peers' side, who are closer with me.

Items measuring guanxi building with supervisors ${ }^{[19]}$ (1 = strongly disagree, $7=$ strongly agree) .

1. During holidays or after office hours, 1 would call my supervisor or visit them.
2. I invite my supervisor for lunch or dinner.

3. On special occasions such as birthday of my supervisor, I would definitely visit them and send gifts.

4. I always actively share with my supervisor about my thoughts, problems, needs and feelings.

5. I care about and have a good understanding of my supervisor's family and work conditions.

6 When there are conflicting opinions, I will definitely stand on my supervisor's side.

Items measuring organizational socialization ${ }^{[20]}$ (1=strongly disagree to $7=$ strongly agree)

1. I know the specific names of the products/services produced/provided by this organization.

2. I know the history of this organization (e.g., when and who founded the company, original products/services, how the organization survived tough times).

3. I know the structure of the organization (e.g., how the departments fit together).

4. I understand the operations of this organization (e.g., who does what, how sites, subsidiaries and/or branches contribute).

5. I understand this organization's objectives and goals.

6. I understand how various departments, subsidiaries, and/or sites contribute to this organization's goals.

7. I understand how my job contributes to the larger organization.

8. I understand how to act to fit in with what the organization values and believes.

9. I know this organization's overall policies and/or rules (e.g., compensation, dress code, smoking, travel expense limitations).

10. I understand the internal politics within this organization (e.g., chain of command, who is influential, what needs to be done to advance or maintain good standing).

11. I understand the general management style (e.g., top-down, participative) used in this organization.

12. I understand what is meant when members use language (e.g., acronyms, abbreviations, nicknames) particular to this organization. 